\title{
Vocal Behavior and Vocal Central Pattern Generator Organization Diverge among Toadfishes
}

\author{
Boris P. Chagnaud ${ }^{a, b}$ Andrew H. Bass ${ }^{b}$ \\ a Department of Biology II, Ludwig Maximilian University of Munich, Planegg-Martinsried, Germany; \\ ${ }^{b}$ Department of Neurobiology and Behavior, Cornell University, Ithaca, N.Y., USA
}

\section{Key Words}

Vocalization - Vocal central pattern generator - Hindbrain .

Teleost fish · Toadfish

\begin{abstract}
Among fishes, acoustic communication is best studied in toadfishes, a single order and family that includes species commonly known as toadfish and midshipman. However, there is a lack of comparative anatomical and physiological studies, making it difficult to identify both shared and derived mechanisms of vocalization among toadfishes. Here, vocal nerve labeling and intracellular in vivo recording and staining delineated the hindbrain vocal network of the Gulf toadfish Opsanus beta. Dextran-biotin labeling of the vocal nerve or intracellular neurobiotin fills of motoneurons delineated a midline vocal motor nucleus (VMN). Motoneurons showed bilaterally extensive dendritic arbors both within and lateral to the paired motor nuclei. The motoneuron activity matched that of the spike-like vocal nerve motor volley that determines the natural call duration and frequency. Ipsilateral vocal nerve labeling with biocytin or neurobiotin yielded dense bilateral transneuronal filling of motoneurons and coextensive columns of premotor neurons. These pre-
\end{abstract}

motor neurons generated pacemaker-like action potentials matched 1:1 with vocal nerve and motoneuron firing. Transneuronal transport further revealed connectivity within and between the pacemaker-motor circuit and a rostral prepacemaker nucleus. Unlike the pacemaker-motor circuit, prepacemaker firing did not match the frequency of vocal nerve activity but instead was predictive of the duration of the vocal nerve volley that codes for call duration. Transneuronally labeled terminal-like boutons also occurred in auditory-recipient hindbrain nuclei, including neurons innervating the inner ear and lateral line organs. Together with studies of midshipman, we propose that separate premotor populations coding vocal frequency and duration with direct premotor coupling to auditory-lateral line nuclei are plesiomorphic characters for toadfishes. Unlike in midshipman, transneuronal labeling in toadfishes reveals an expansive column of pacemaker neurons that is weakly coupled to prepacemaker neurons, a character that likely depends on the extent of gap junction coupling. We propose that these and other anatomical characters contribute to neurophysiological properties that, in turn, sculpt the species-typical patterning of frequency and amplitude-modulated vocalizations.

(c) 2014 S. Karger AG, Basel

\section{KARGER}

E-Mail karger@karger.com

www.karger.com/bbe
(C) 2014 S. Karger AG, Basel

0006-8977/14/0841-00051\$39.50/0
Dr. Andrew H. Bass

Department of Neurobiology and Behavior

Cornell University

Ithaca, NY 14853 (USA)

E-Mail ahb3@ cornell.edu 


\begin{tabular}{ll}
\hline Abbreviations used in this paper \\
\hline AM & amplitude modulation \\
Ax & axon \\
Cb & cerebellum \\
CeC & central canal \\
CPG & central pattern generator \\
Den & dendrite \\
DOri & descending octaval nucleus \\
FM & frequency modulation \\
FN & funicular nucleus \\
g & grunt \\
h & hoot \\
IO & inferior olive \\
LB & lateral brainstem bundle \\
Mid & midbrain \\
MLF & medial longitudinal fasciculus \\
OB & olfactory bulb \\
OCC & occipital nerve root \\
OEN & octavolateral efferent nucleus \\
PB & phosphate buffer \\
SUP & supramedullary nucleus \\
Tel & telencephalon \\
VMN & vocal motor nucleus \\
VN & vocal nerve \\
VoTr & vocal tract \\
VPN & vocal pacemaker nucleus \\
VPP & vocal prepacemaker nucleus \\
VT & ventral tegmental area \\
Vtr & vourth ventricle \\
X & \\
\hline & \\
& vagal nerve \\
\hline
\end{tabular}

\section{Introduction}

Vocalizations provide examples of rhythmic motor behaviors - they are often repetitive, stereotyped, and have a predictable temporal pattern [see Bradbury and Vehrencamp, 2011]. Among tetrapods, the central control of vocalization depends on the spatiotemporal patterning of respiratory-related muscles together with one or more pairs of muscles dedicated to sound production [Bass, 1989; Nowicki et al., 1992; Bass and Baker, 1997]. An exception is the family of fully aquatic pipid frogs [Yager, 1992], although glottal motor activity is still strongly coupled to vocal output [Zornik and Kelley, 2008]. Sound production in fishes does not exhibit a similar dependency on respiration and often involves the vibration of either a gas-filled swim bladder or other skeletal structures such as part of the pectoral girdle [Ladich and Fine, 2006; Bass and Ladich, 2008]. While anatomical investigations have identified a sonic or vocal motor nucleus (VMN) in several groups of distantly related teleost fishes [for reviews, see Bass and Baker, 1991; Onuki and Somiya, 2007; Bass and Ladich, 2008; Boyle et al., 2013; Bass et al., in press], most neurophysiological studies of the vocal motor system have been on toadfishes, a single order (Batrachoidiformes) and family (Batrachoididae) that includes species commonly known as midshipman and toadfish [Greenfield et al., 2008].

Toadfishes and midshipman have a single pair of sonic swim bladder muscles that generate highly stereotyped, pulsatile vocalizations (fig. 1a, b). The call structure of sonic fishes can differ in duration, pulse repetition rate (which also sets the fundamental frequency in fishes), and frequency (FM) and amplitude (AM) modulation [see Amorim, 2006; Rice and Bass, 2009]. Gulf toadfishes (Opsanus beta), the focus of this report, have two main classes of vocalizations known as 'boatwhistles' and 'grunts' made by territorial males during courtship and agonistic encounters, respectively; females are only known to make grunts [Fish and Mowbray, 1970; Maruska and Mensinger, 2009; Thorson and Fine, 2002]. Grunts are typically brief in duration $(<300 \mathrm{~ms})$ and broadband. Advertisement boatwhistles typically include one or more brief introductory grunts followed by a longer-duration ( 200-600 ms) 'hoot' or 'boop' that has an initial gruntlike segment consistently followed immediately by a multiharmonic hoot and, in some cases, a final very brief grunt-like segment (fig. 1a) [Tavolga, 1958; Thorson and Fine, 2002; Remage-Healey and Bass, 2005].

Sonic muscles in toadfishes are innervated by paired occipital nerve roots (OCC-1 and OCC-2; fig. 1c) largely comprised of VMN axons and considered homologues of hypoglossal nerve roots [Bass and Baker, 1990, 1991; Bass et al., 2008]. 'Swim bladder motoneurons' were first identified in the oyster toadfish (O. tau) [Bennett and Pappas, 1965; Pappas and Bennett, 1966; Bennett et al., 1985; Weiser et al., 1985]. These early studies also noted the presence of electrotonic coupling, synchrony, and inhibitory input within the premotor-motor circuitry. Later studies of several teleosts, including the oyster toadfish, emphasized the temporal matching between the natural call pulse repetition rate/fundamental frequency and the spike-like motor volley recorded from OCC [Bass and Baker, 1991; Bass et al., 2008]. The motor volleys of each vocal nerve (VN) fire in phase [Bass and Baker, 1991], with each VN spike reflecting the synchronous activity of the motoneurons [Bennett and Pappas, 1965; Pappas and Bennett, 1966; Bennett et al., 1985] that activate the ipsilateral muscle [Skoglund, 1961]. Hence, the firing frequency and duration of the VN motor volley determine the natural call features, with each VN spike coding for
Chagnaud/Bass 


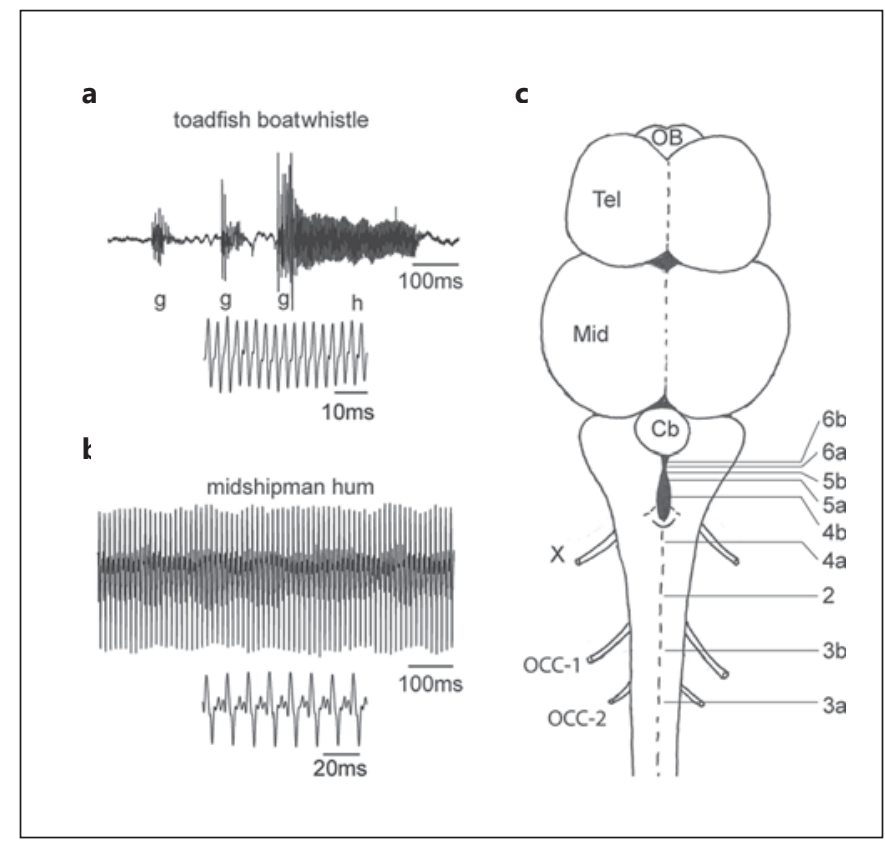

Fig. 1. Toadfishes differ in terms of their vocal repertoire. Representative hydrophone recordings of vocalizations shown on two time scales. a Gulf toadfish (O. beta) boatwhistle that includes a series of introductory grunts $(\mathrm{g})$ followed by a hoot $(\mathrm{h})$. The lower record is the portion of the hoot on an expanded time scale. b Plainfin midshipman ( $P$. notatus) hum. The lower record is the portion of the hum on an expanded time scale. c Schematic drawing of a Gulf toadfish brain with pairs of OCC that carry vocal motoneuron axons that innervate the ipsilateral swim bladder muscle. The vagal nerve $(\mathrm{X})$ is shown for orientation. Horizontal lines indicate the relative levels of the photographs shown in figures 2-6. $\mathrm{Cb}=$ Cerebellum; Mid = midbrain; $\mathrm{OB}=$ olfactory bulb; Tel = telencephalon.

one vocal muscle contraction that directly translates into a single sound pulse [Skoglund, 1961; Cohen and Winn, 1967]. Herein lies a major advantage of studying the neural basis of vertebrate sound production in toadfishes and fishes in general - a simple translation between the neural output and the physical attributes of the behavior itself.

Most studies of central vocal mechanisms among toadfishes are for the plainfin midshipman fish (Porichthys notatus) that produces grunts like the toadfish and advertisement calls known as 'hums' that function like the courtship boatwhistles of toadfishes (fig. 1b) [Brantley and Bass, 1994; Bass et al., 1999; McIver et al., 2014]. Intracellular recordings in midshipman have demonstrated that the duration, frequency/pulse repetition rate, and amplitude of the VN motor volley, and hence natural calls, are determined by separate populations of vocal prepacemaker nuclei (VPP), vocal pacemaker nuclei
(VPN), and VMN, respectively [Chagnaud et al., 2011, 2012]. The main goal here was to use transneuronal tracing to provide a broad organizational overview of the hindbrain vocal system of the Gulf toadfish and then compare it to that of the plainfin midshipman. Intracellular recording was only used to compare the general activity patterns of vocal neurons in the Gulf toadfish to those matching the location of vocal motor, pacemaker, and prepacemaker neurons in midshipman and not to carry out a quantitatively rigorous neurophysiological analysis as in our prior studies [Chagnaud et al., 2011, 2012].

We specifically chose the Gulf toadfish for comparison to the midshipman fish because of the abundance of prior field and laboratory studies investigating behavioral, auditory, and hormonal mechanisms of acoustic communication in this species of toadfish [Tavolga, 1958; Demski and Gerald, 1972, 1974; Walsh et al., 1995; Bass et al., 2001; Thorson and Fine, 2002; Remage-Healey and Bass, 2005, 2006; Remage-Healey et al., 2006; Fine and Thorson, 2008]. This study is a first step in testing the hypothesis that the diversity in vocal attributes such as duration and patterns of AM and FM among toadfishes (e.g. fig. 1a, b) is paralleled by divergent patterns in the organization of the central vocal network. Despite the close phylogenetic relationship of the Gulf toadfish and the plainfin midshipman [Rice and Bass, 2009], the results show that the vocal central pattern generator (CPG) anatomy of these two species differs at the levels of both the pacemaker-motoneuron circuit and the afferent prepacemaker neurons.

\section{Materials and Methods}

\section{Animals}

Gulf toadfish juveniles ( $\mathrm{n}=5$ males and 2 females; $4.5-8.0 \mathrm{~cm}$ in standard length) that were only used for $\mathrm{VN}$ labeling were kindly provided by Dr. Peggy Edds-Walton, while adults that were only used for intracellular staining and neurophysiology $(n=15 ; 12.2-$ $25.7 \mathrm{~cm}$ in length; male or female not recorded) were obtained from a commercial source (Gulf Specimen, Panacea, Fla., USA). We used juveniles for nerve labeling because transneuronal transport is maximal in smaller animals [Bass et al., 1994, 1996, 2008; Bass, pers. obs.]. Adults were used for neurophysiology, inclusive of intracellular recording and staining of vocal neurons, because they were readily available from commercial sources. Our goal was to provide a broad organizational overview of the hindbrain vocal system and not to study in depth either the ontogeny or the sex differences in vocal mechanisms.

VN Labeling

The cut end of one VN at the level of the swim bladder was labeled with crystals of $10 \mathrm{kDa}$ dextran-biotin (Molecular Probes, 
Eugene, Oreg., USA) (see fig. 2), biocytin (Sigma-Aldrich), or neurobiotin (Vector Laboratories, Burlingame, Calif., USA) (see fig. 3-6). Following survival times of 26 h to 11 days, animals were deeply anesthetized by immersion in water with tricaine methane sulfonate (MS-222). Anesthesia differed from that described above for adults as the protocol changed between the years when the experiments were performed. Transcardial perfusion was performed as described above, but the fixative was $4 \%$ paraformaldehyde/ $1.0 \%$ glutaraldehyde in $0.1 \mathrm{M}$ phosphate buffer (PB) [see Bass et al., 1994, for details of the surgery and labeling]. Brains were postfixed in the same solution for $1 \mathrm{~h}$, stored at $4^{\circ} \mathrm{C}$ in $0.1 \mathrm{M} \mathrm{PB}$, and then transferred to a $30 \%$ sucrose $/ 0.1 \mathrm{M} \mathrm{PB}$ solution at $4^{\circ} \mathrm{C} \leq 24 \mathrm{~h}$ prior to being sectioned frozen at $50 \mu \mathrm{m}$. The biotin reaction product was visualized using an avidin:biotinylated horseradish peroxidase complex (Elite Kit; Vector Laboratories) [see Bass et al., 1994, for details]. The staining protocol differed from that described above for intracellular staining as the protocol had improved by the time the neurophysiology experiments were performed. Sections were counterstained with cresyl violet and then treated as above prior to being coverslipped.

\section{Morphometry}

The numbers of vocal motor (VMN) and premotor pacemaker (VPN) neurons were counted in the entire brains of 5 cases (biocytin, $\mathrm{n}=4$; neurobiotin, $\mathrm{n}=1$ ) with extensive bilateral, transneuronal labeling of VMN and VPN. All labeled neurons were counted at a magnification of $\times 250$ using a Leitz drawing tube, attached to a Leitz Dialux 22 microscope. The average soma diameter (average of the minor and major axes) was also determined for each of $10 \mathrm{VMN}$ and 8-10 VPN neurons for a single transverse section in the middle of the VMN-VPN circuit of the biocytin- and neurobiotin-labeled brains (see fig. 4a). The average diameter of the VMN and VPN neurons was less than $20 \mu \mathrm{m}$ (see Results). Given that the section thickness was $50 \mu \mathrm{m}$ (see above), double counting of somata between sections was of minimal concern.

\section{Neurophysiology}

The surgical and neurophysiological methods described previously in studies of midshipman fishes [Bass and Baker, 1990; Chagnaud et al., 2011] were approved by the Cornell University Institutional Animal Care and Use Committee. For intracellular studies, animals were deeply anesthetized [immersion in $0.025 \%$ benzocaine (ethyl p-amino benzoate); Sigma, St. Louis, Mo., USA] and a dorsal craniotomy was performed to expose the brainstem, the rostral spinal cord, and all cranial and rostral spinal nerves. After surgery, animals received an intramuscular injection of bupivacaine anesthetic (0.25\%; Abbott Laboratories, Chicago, Ill., USA) with $0.01 \mathrm{mg} \cdot \mathrm{ml}^{-1}$ epinephrine (International Medication Systems, El Monte, Calif., USA) near the wound site and then an intramuscular trunk injection of the muscle relaxant pancuronium bromide $(0.1-1 \mu \mathrm{g} / \mathrm{g}$ of body weight). Animals were placed in a Plexiglas tank and perfused over the gills with artificial seawater at $18-20^{\circ} \mathrm{C}$, the same temperature as their home aquarium water.

Teflon-coated, silver wire electrodes ( $75 \mu \mathrm{m}$ in diameter) with exposed ball tips (50-100 $\mu \mathrm{m}$ in diameter) were used to record the vocal motor volley from ventral OCC (see VN, fig. 2d, 4c, 5e). For antidromic stimulation, bipolar silver wire electrodes insulated with enamel except at the tips $(0.15 \mathrm{~mm}$ in diameter; $0.3 \mathrm{~mm}$ between tips) were implanted at the level of the swim bladder be- tween each muscle and the bladder wall, immediately adjacent to the occipital nerve. Glass micropipettes (resistance 35-50 M $\Omega$ ) were filled with a $5 \%$ neurobiotin solution in $0.5 \mathrm{M} \mathrm{KCOOH}$ and used for intracellular recordings and iontophoretic neurobiotin injections (5-10 nA positive current, 2-15 min, 50\% duty cycle) (see VMN, fig. 2d, lower right inset; VPN, fig. 4c, lower left inset; VPP, fig. 5e, lower left inset). Recordings were performed from the dendrite/soma of VMN neurons, from the dendrites and axons of VPN neurons, and from the axons of VPP neurons.

At the conclusion of an experiment, juvenile and adult fish were deeply anesthetized by immersion in water with benzocaine (see above). For those experiments that included intracellular filling of neurons, animals were sacrificed $2-6 \mathrm{~h}$ after the neurobiotin injections and then perfused transcardially with a teleost Ringer's solution followed by an ice-cold solution of 3.5\% paraformaldehyde $/ 0.5 \%$ glutaraldehyde dissolved in $0.1 \mathrm{M} \mathrm{PB}$. Brains were removed from the skull, stored in $0.1 \mathrm{M} \mathrm{PB}$ at $4^{\circ} \mathrm{C}$, and then transferred to a $30 \%$ sucrose $/ 0.1 \mathrm{M} \mathrm{PB}$ solution at $4^{\circ} \mathrm{C} \leq 24 \mathrm{~h}$ prior to being sectioned frozen at $100 \mu \mathrm{m}$. A neurobiotin reaction product was visualized using a modified d-aminobenzidine protocol. DAminobenzidine-reacted sections were mounted and then counterstained with cresyl violet before dehydration through a graded series of alcohols followed by xylene, and then coverslipped.

Neurobiotin-filled neurons were reconstructed at a magnification of $\times 400$ with the aid of a Leitz drawing tube attached to a Leitz Dialux 22 microscope (see fig. 2d, 4c, 5e, f). Photomicrographs of neurobiotin-labeled neurons were taken with either a $35-\mathrm{mm}$ Nikon FDX-35 camera attached to a Nikon Eclipse E-800 microscope (Kodak Gold color film, ISO 100) or a SPOT digital camera attached to the Nikon microscope. Image stacks of photographs taken on different optical planes were combined into a single image using a commercial program (Zerene Stacker).

\section{Results}

\section{Vocal Motor Nucleus}

Dextran-biotin $(10 \mathrm{kDa})$ labeling of one $\mathrm{VN}$ at the level of the swim bladder resulted in labeling of the ipsilateral pair of occipital $\mathrm{VN}$ roots that gave rise to the vocal tract (VoTr) and the VMN comprising round, ovoid, and pear-shaped somata (fig. 2a, b). The VMN is bordered ventrally by the medial longitudinal fasciculus (MLF; fig. 2a) and dorsally by either the fourth ventricle (Vtr; fig. 2a) or the central canal at the rostral and caudal levels, respectively. Dextran-biotin fills of a single VN clearly distinguished the midline boundary between the pair of midline motor nuclei (fig. 2a, b). Motoneuron dendritic trees branched extensively within the contralateral VMN and bilaterally outside the confines of the VMN, extending toward the lateral surface of the brain and the rostral spinal cord (fig. 2a, b). Dendrites occasionally extended ventrally into and across the MLF.

Fifteen antidromically identified motoneurons were intracellularly recorded and filled with neurobiotin. Sin- 

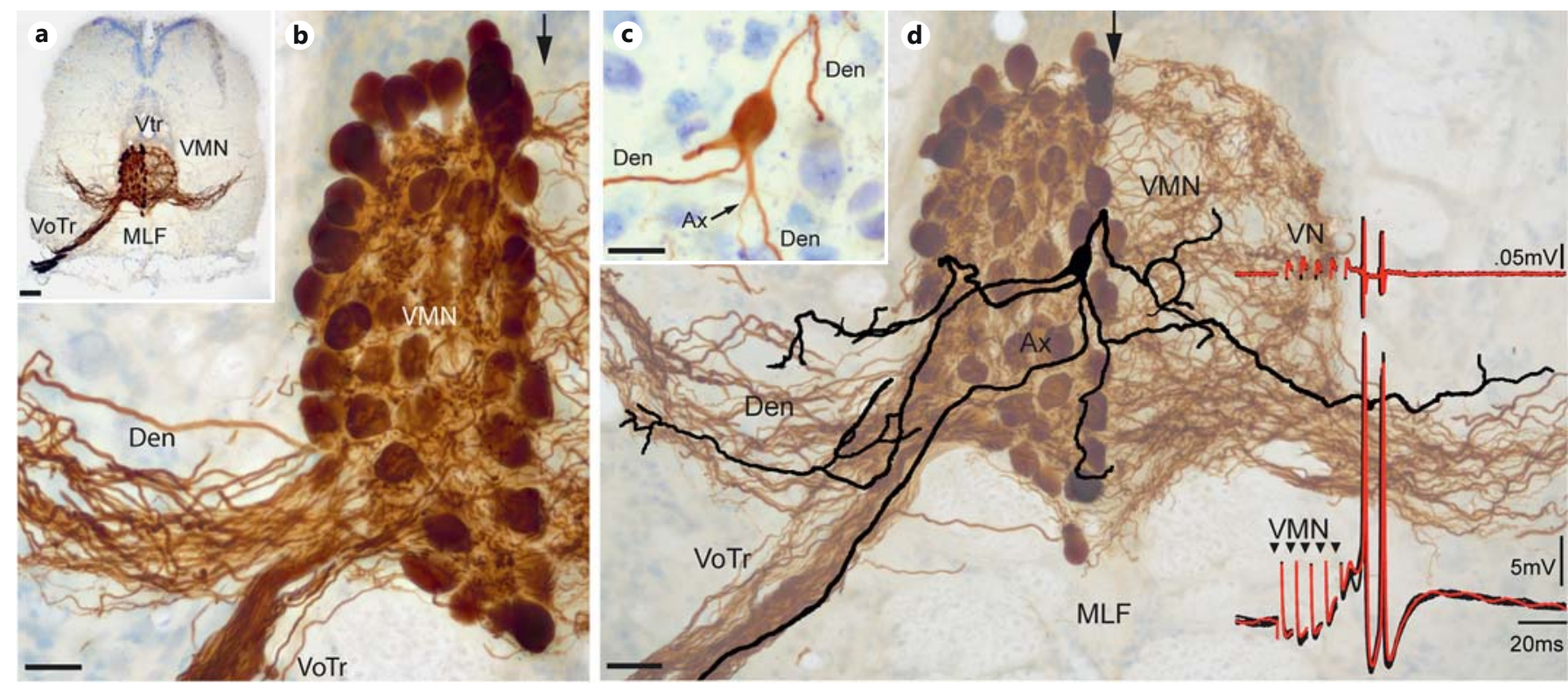

Fig. 2. VMN of the Gulf toadfish. a Hindbrain section showing VMN positioned ventral to the Vtr and dorsal to the MLF at the level indicated in figure 1c. The ipsilateral VMN is retrogradely labeled after ipsilateral VN labeling with $10-\mathrm{kDa}$ dextran-biotin. VMN dendrites extend across midline to contralateral VMN and bilaterally outside the paired VMN. VMN axons exit via the ipsilateral VoTr. $\mathbf{b}$ Close-up of photograph of a section adjacent to $\mathbf{a}$. Den $=$ Dendrites. The arrow indicates the midline. $\mathbf{c}$ Photograph of an intracellular neurobiotin-filled motoneuron. The arrow indicates the branching point of the axon ( $\mathrm{Ax}$ ) from a proximal dendrite. d Camera lucida reconstruction of the motoneuron shown in c superimposed (not to scale) on a photograph of VMN retrogradely filled via dextran amine labeling of the ipsilateral VN (taken from another experiment after nerve labeling, also shown in a). The arrow indicates the midline. The inset shows, for this reconstructed motoneuron, superimposed intracellular records of action potential firing (black traces with one highlighted in red) (lower inset) and corresponding VN activity (upper inset) following midbrain electrical stimulation (colors refer to the online version only). An electrical artifact is indicated by inverted triangles. Scale bars $=100 \mu \mathrm{m}(\mathbf{a}), 30 \mu \mathrm{m}(\mathbf{b}, \mathbf{c})$, and $35 \mu \mathrm{m}(\mathbf{d})$. gle motoneurons had 4-5 proximal dendrites with secondary branches extending bilaterally throughout the VMN (fig. 2c, d). Axons lacked collaterals and arose from either a somatic initial segment $(n=9)$ or a proximal dendrite ( $\mathrm{n}=6$; fig. $2 \mathrm{c}, \mathrm{d})$. VMN neurons were not spontaneously active but discharged action potentials during midbrain, electrically evoked responses that were temporally matched 1:1 with each VN spike (fig. 2 d, right inset).

\section{Vocal Premotor Network}

Application of either neurobiotin or biocytin to one $\mathrm{VN}$ at the level of the swim bladder always $(\mathrm{n}=6)$ resulted in dense, bilateral labeling of the VN tracts, both motor nuclei and columns of premotor, fusiform-shaped somata that were lateral and ventral to the VMN (fig. 3a, b, $4 a-c)$. The premotor columns in toadfishes were at the same location as the VPN somata in midshipman fish, so we followed that nomenclature here [Bass and Baker, 1990; Chagnaud et al., 2011]. Intracellular recording ( $\mathrm{n}=$
$20)$, in some cases coupled to neurobiotin fills $(n=3)$, showed that these premotor neurons had the same temporal firing properties as VPN in midshipman, namely a 1:1 match with VN spikes (fig. 4c, lower left inset) [Bass and Baker, 1990; Chagnaud et al., 2011].

Pacemaker neurons extended 1,000-1,350 $\mu \mathrm{m}$ from rostral to caudal VMN levels, with extensive crossing of processes both dorsal to the VMN and ventral, across the MLF (fig. 3a, b, 4a, c). The rostral $250-350 \mu \mathrm{m}$ of the VPN-VMN circuit overlapped the caudal extent of the inferior olive (IO; fig. 4b). Pacemaker somata and/or processes extended $50-100 \mu \mathrm{m}$ caudal to the VMN in 4 of 6 specimens but did not extend to the far rostral limits of the VMN (fig. 4b). Motoneuron somata were observed ventrolateral to the VMN within the ipsilateral occipital tract at far rostral levels (fig. $4 \mathrm{~b}$, inset).

The pacemaker column became more expansive in its mediolateral extent at progressively rostral levels (fig. 3a, b, 4a). This appeared to be due to an increase in the den- 
sity of both labeled somata and processes. Dense bilateral filling of processes along the lateral extent of VMN extended to the surface of the hindbrain and spinal cord (fig. 3, 4). This dense filling reflects both the extensive dendritic arborization of motoneurons (fig. $2 \mathrm{a}, \mathrm{b}, 4 \mathrm{~b}$, inset) and the dendritic and axonal branching of pacemaker neurons (fig. 4c). Pacemaker axons terminated bilater-

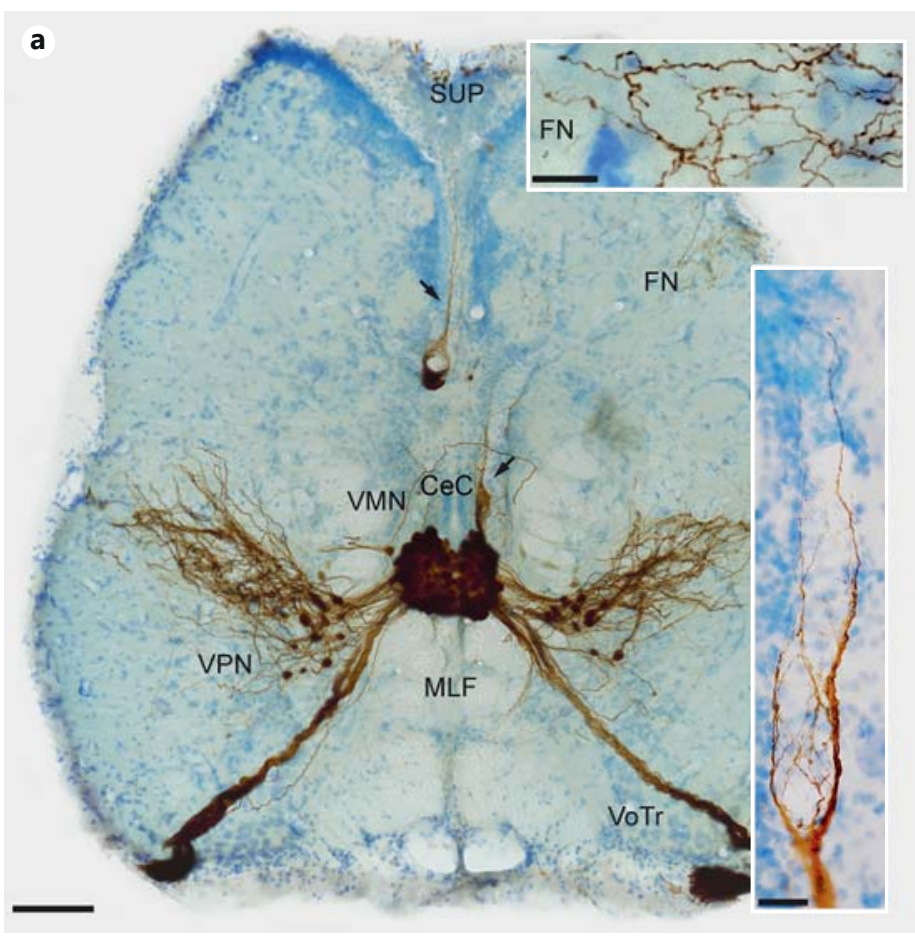

ally within the VMN and the dense cluster of processes lateral to the VMN. Transneuronally labeled VPN somata were also found close to intracellularly filled neurons in all cases (arrows in fig. 4c, lower right inset).

The average soma diameter for VMN and VPN in 5 biocytin and neurobiotin brains was $17.9 \mu \mathrm{m}(\mathrm{SD}=1.6)$ and $12.9 \mu \mathrm{m}(\mathrm{SD}=0.4)$, respectively (see Materials and
Fig. 3. Caudal vocal CPG network in the Gulf toadfish. Caudal hindbrain sections showing the vocal CPG at the levels indicated in figure $1 \mathrm{c}$ after labeling of one $\mathrm{VN}$ with neurobiotin. $\mathbf{a}, \mathbf{b} \mathrm{VMN}$ and VPN are bilaterally labeled. The arrows dorsal to VMN indicate the dorsal fiber tract, highlighted in the lower inset in a (from an adjacent section), that projects to the SUP along the dorsal surface of the brain, while the upper inset shows the terminal field

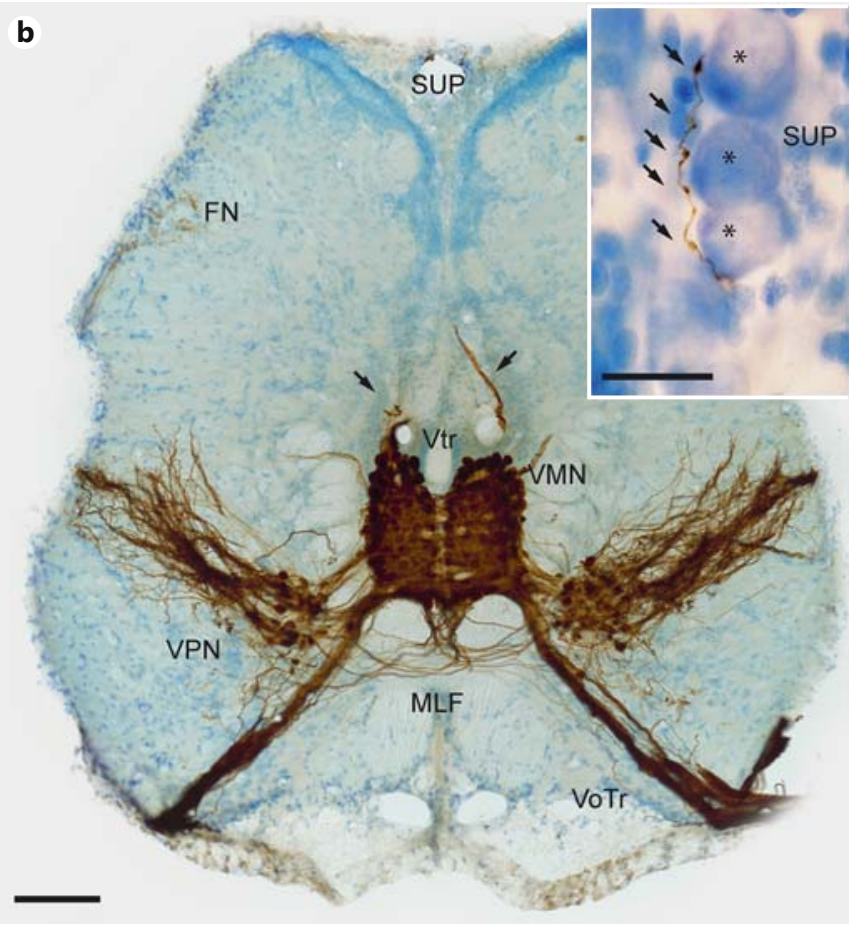

within the funicular nucleus. The inset in $\mathbf{b}$ (from an adjacent section) shows terminal, bouton-like structures (arrows) apposed to supramedullary somata (somata marked by asterisks), originating from the dorsal tract. $\mathrm{FN}=$ Funicular nucleus; $\mathrm{CeC}=$ central canal. Scale bars $=100 \mu \mathrm{m}(\mathbf{a}, \mathbf{b}), 25 \mu \mathrm{m}$ (insets in a), and $15 \mu \mathrm{m}$ (inset in b).

biotin-filled VPN neuron. A photograph of the filled soma of the reconstructed VPN neuron, positioned in the VPN column, is highlighted in the lower right inset; also apparent are nearby lightly filled, transneuronally labeled VPN somata (arrows). Axonal arbor densely innervates the paired VMN and projects to the contralateral VPN. The lower left inset shows superimposed intracellular records of a reconstructed VPN neuron and corresponding VN activity (black traces with one highlighted in red; colors refer to the online version only). An electrical artifact is indicated by inverted triangles. Scale bars $=125 \mu \mathrm{m}(\mathbf{a}-\mathbf{c}), 25 \mu \mathrm{m}$ (inset in a), $20 \mu \mathrm{m}$ (lower right inset in c), and $45 \mu \mathrm{m}$ (inset in b).

(For figure 4 see next page.) 

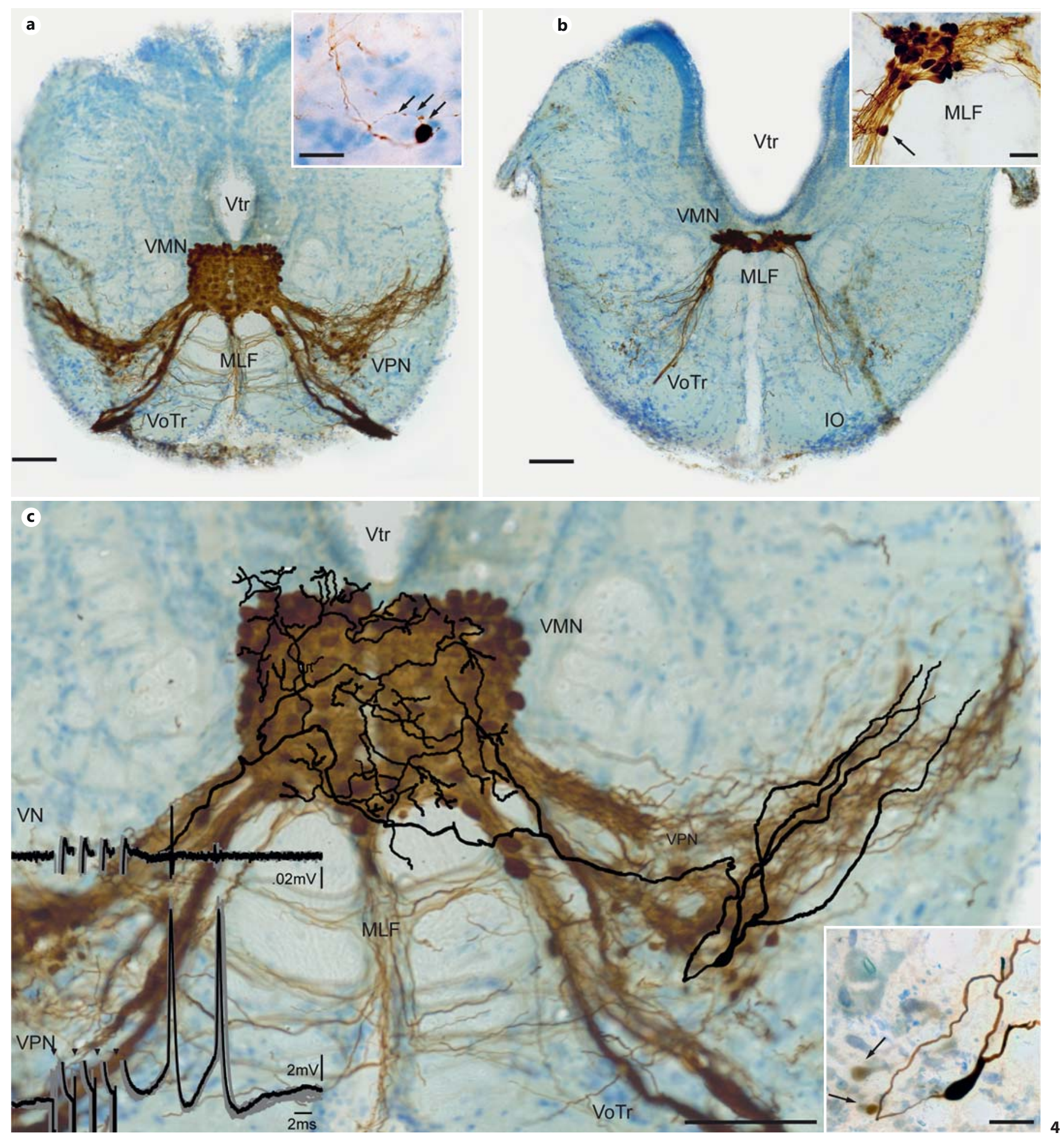
Methods for more details). For these same brains, the average number of VMN and VPN neurons was 1,021 $(\mathrm{SD}=169)$ and $322(\mathrm{SD}=91)$, respectively (see Materials and Methods for more details).

\section{Vocal-Motor Coupling to Supramedullary Neurons}

Transneuronal neurobiotin and biocytin transport revealed a thick fiber bundle with collaterals that arched dorsally toward the midline at caudal VMN levels, just above the central canal and Vtr (fig. 3a, b). On average ( $\mathrm{n}=6$ fishes), the dorsal bundle had a rostral-caudal extent of $360 \mu \mathrm{m}$ (range $250-450 \mu \mathrm{m}$ ), beginning $150 \mu \mathrm{m}$ from the caudal end of the VMN (range 0-200 $\mu \mathrm{m}$ ). In the case illustrated in figure 3 , the dorsal bundle had a rostral-caudal extent of $300 \mu \mathrm{m}$, beginning $150 \mu \mathrm{m}$ from the caudal end of the VMN. Labeled processes branched off the dorsal bundle bilaterally, extending mainly towards either the contralateral VMN or the column of supramedullary neurons (supramedullary nucleus; SUP) that are clustered along the dorsal aspect of the spinal cord and the caudal hindbrain (fig. 3a and lower right inset). Terminal-like boutons were directly apposed to supramedullary somata (fig. $3 \mathrm{~b}$, inset).

In all neurobiotin and biocytin cases, labeled axons entered a dorsal root at the level of the VMN and formed terminal-like boutons within the funicular nuclei (fig. 3a). There was no indication that labeled afferents innervated any part of the motor column. The source of the dorsal root afferents remains unknown.

\section{Vocal Prepacemaker Nucleus}

Transneuronally labeled processes and terminal-like varicosities were abundant immediately rostral to the VPN-VMN (fig. 5a, b). In 5 of 6 cases, varicosities surrounded lightly-filled, ovoid-shaped somata corresponding in position to the VPP in adult and larval midshipman fishes, so we followed that nomenclature here [first identified as the ventral medullary nucleus in Bass et al., 1994; Bass et al., 2008; Chagnaud et al., 2011] (fig. 5a-c). In 1 case the VPP was continuous with the VPN column, while in the remaining 4 cases it was separated by $50-100$ $\mu \mathrm{m}$. Dense terminal-like varicosities spanned the midline at VPP levels (fig. 5b, d). The light staining of VPP somata, together with numerous terminal-like endings along their perimeter (fig. 5c), suggested that VPP somata were filled via anterograde transneuronal transport from VPN axons rather than from VMN neurons. VPP had a rostral-caudal extent of 200-350 $\mu \mathrm{m}$. The most extensive transneuronal label throughout the VMN-VPNVPP network occurred after a survival time of 3 days and the least extensive one occurred after a survival time of 11 days.

Intracellular neurobiotin fills $(\mathrm{n}=3)$ showed fusiformshaped VPP somata with extensive dendritic branching at the level of the VPP (fig. 5e and upper right inset) and an axon that terminated extensively within the VPN column and within VMN (fig. $5 f$ and insets). VPP neurons $(\mathrm{n}=15)$ did not fire in a 1:1 pattern matched to fictive call spikes (fig. 5c, lower left inset), but instead the VPP action potential firing duration was predictive of the duration of the $\mathrm{VN}$ volley (the intracellular record in fig. 5e shows axonal activity).

\section{Vocal Coupling to the Inner Ear and Lateral Line}

In all cases of transneuronal labeling via the $\mathrm{VN}$, a lateral brainstem bundle [LB; nomenclature after Bass et al., 1994] gave rise to putative terminals along the lateral brainstem extending from the VPP to the cerebellum (fig. 6a, b). This bundle likely arose from the VPN column, the only population of densely filled premotor somata. Terminal-like boutons were found around the ovoid-shaped somata in the octavolateral efferent nucleus (OEN; fig. 6a and inset) that directly innervates the inner ear and lateral line organs [Highstein and Baker, 1986; Bass et al., 1994; Weeg et al., 2005]. Labeling was more extensive in a rostral subdivision of the efferent nucleus (separated from a caudal subdivision by internal arcuate fibers), with the label extending ventrolaterally to the efferent nucleus along a trajectory consistent with that of efferent neuron dendrites (arrows in fig. 6a) [see Bass et al., 1994, for midshipman fishes; see Highstein and Baker, 1986, for toadfishes].

Processes and putative terminals also occurred further rostrally at the level of the eighth nerve-recipient auditory nuclei [Highstein, 1992; see Bass et al., 2000, for midshipman fishes and Bass et al., 2001, for Gulf toadfish cytoarchitecture]. In 4 out of 6 cases, pear-shaped somata were lightly filled in a rostral, intermediate subdivision of the descending octaval nucleus (DOri; fig. 6b and upper inset). Faintly labeled DOri processes were followed ventrally into a ventral tegmental area (VT; fig. $6 \mathrm{~b}$ and lower inset) where they were covered with densely filled terminal-like boutons, the likely site of anterograde transneuronal transport of biocytin to DOri. The VT and DOri neurons formed a continuum [Bass et al., 2001]. Labeled processes and terminal-like boutons were dense immediately ventral to the lateral aspect of the cerebellum's eminentia granularis within the rostral hindbrain (not shown); less dense labeling extended into the immediately adjacent eminentia granularis. 
Fig. 5. VPP in the Gulf toadfish. a, b Hindbrain sections at the levels indicated in figure 1c after VN labeling with neurobiotin. c, d Higher magnification of the regions shown in $\mathbf{a}$ and $\mathbf{b}$, respectively (indicated by asterisks), showing transneuronally, lightly filled VPP somata and overlying bouton-like varicosities (c) and densely labeled bouton-like varicosities (d). e Higher magnification view of a with an overlaid partial camera lucida reconstruction of intracellular, neurobiotin-filled VPP neurons (taken from another experiment). The lower left inset shows superimposed intracellular records of a reconstructed VPP neuron and the corresponding $\mathrm{VN}$ activity (black traces with one highlighted in red; colors refer to the online version only). The upper right inset shows a photograph highlighting the soma of a reconstructed VPP neuron. Den $=$ Dendrites; $A x=$ axon. f Partial camera lucida reconstruction of an intracellularly filled axonal arbor of the reconstructed VPP neuron shown in e overlaid on a photograph of the hindbrain section shown in figure $4 \mathrm{a}$. The insets show bouton-like structures apposed to vocal motoneuron (VMN) somata (marked by asterisks; left) and at the level of the VPN (right). Scale bars $=100 \mu \mathrm{m}(\mathbf{a}, \mathbf{b}), 120 \mu \mathrm{m}$ (e), $60 \mu \mathrm{m}(\mathbf{f}), 10 \mu \mathrm{m}(\mathbf{c}, \mathbf{d}$, insets in f), and $40 \mu \mathrm{m}$ (inset in e).
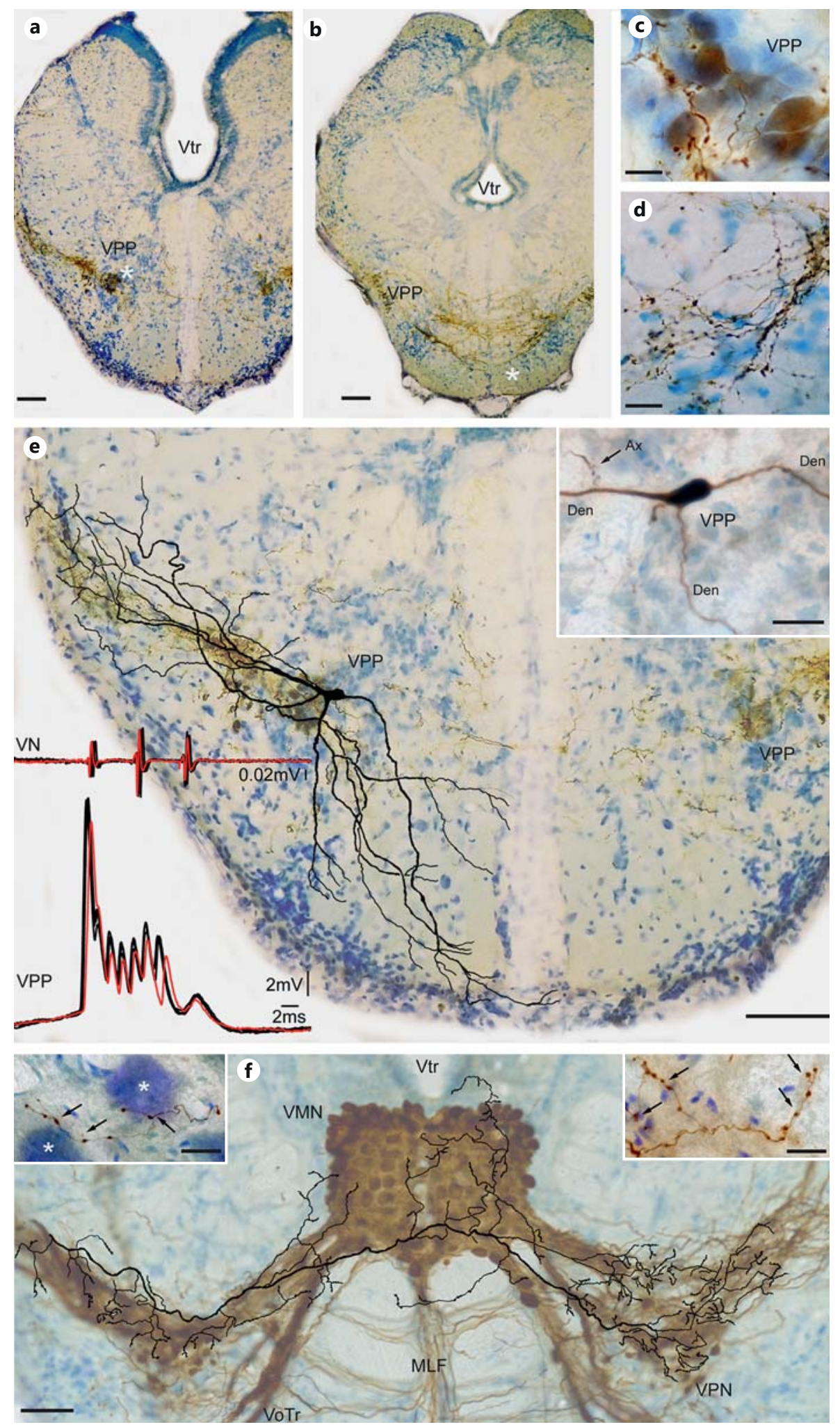
Fig. 6. Anatomical basis for audio-vocal coupling in the Gulf toadfish. a, b Hindbrain sections at the levels indicated in figure 1c after VN labeling with neurobiotin. Shown are projections from the vocal CPG to auditory-related nuclei, including the OEN (a), the DOri (b) and the ventral tegmental nucleus (VT; b). The inset in a shows projection to the OEN, with terminal bouton-like structures surrounding OEN somata (asterisks). The insets in $\mathbf{b}$ show transneuronally filled DOri somata (indicated by arrows) and processes (upper inset), and bouton-like structures in the VT (lower inset). Scale bars $=100 \mu \mathrm{m}(\mathbf{a}$, b), and $15 \mu \mathrm{m}$ (insets in a, b).
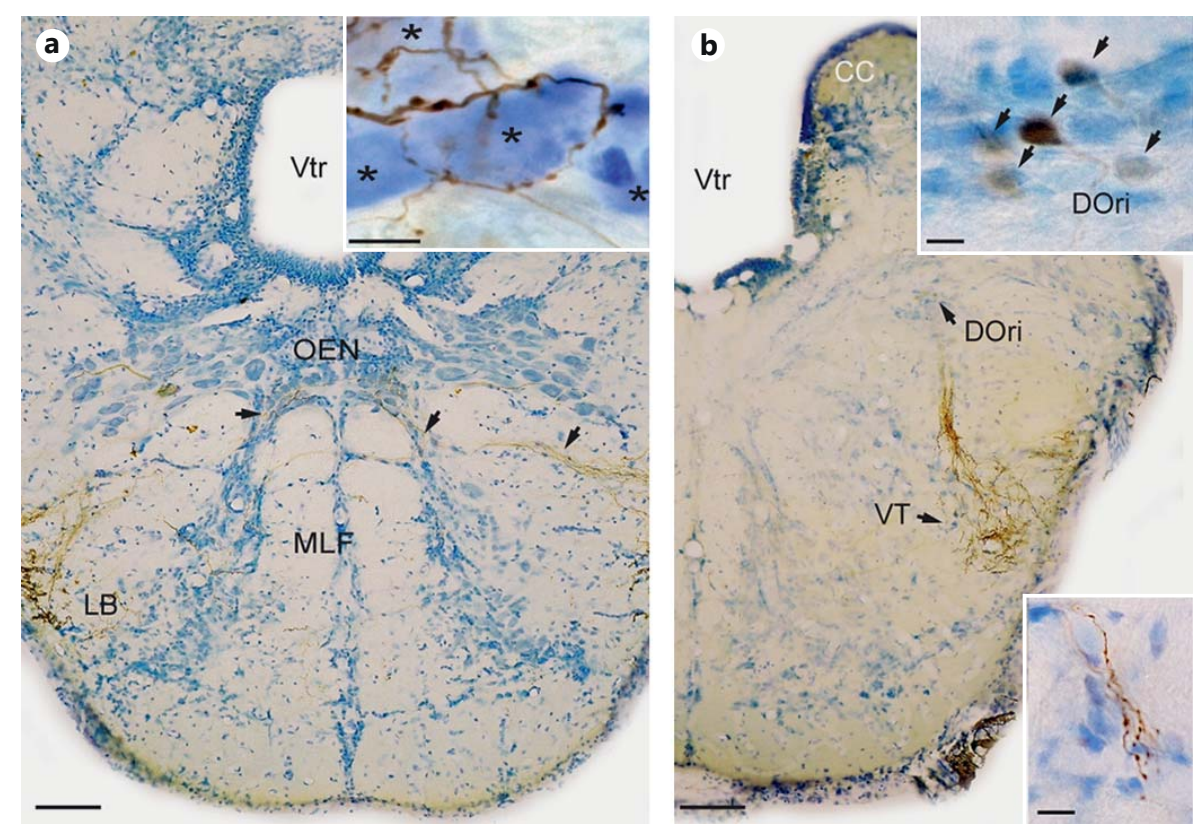

\section{Discussion}

This is the first comprehensive report for any toadfish species other than the midshipman fish of the vocal premotor-motor network and its connectivity to the auditory and lateral line systems. Prior studies of toadfish species in the genus Opsanus presented minimal detail on VMN anatomy and physiology [Pappas and Bennett, 1966; Fine et al., 1984; Bass and Baker, 1991]. Brain stimulation studies by Demski et al. [1973] led to the proposal of a hierarchical organization for central vocal control in the Gulf toadfish. Using a combination of anatomical and physiological methods, we showed that the vocal CPG in the Gulf toadfish has 2 separate premotor nuclei corresponding in morphology and physiology to VPN and VPP in midshipman where VPN and VPP code call fundamental frequency/pulse repetition rate and duration, respectively [Chagnaud et al., 2011]. The results are also consistent with the pattern of connectivity shown in midshipman, whereby the VPP projects to the VPN which, in turn, provides a dense input to the paired VMN [Bass and Baker, 1990; Bass et al., 1994; Chagnaud et al., 2011, 2012].

\section{Vocal CPG}

Neurophysiological studies of the Gulf toadfish have shown that the hindbrain-spinal region containing the VPP-VPN-VMN network can produce a fictive call out- put that mimics the temporal properties of boatwhistles when it is surgically isolated in an otherwise intact preparation [Remage-Healey and Bass, 2006]. We found that VMN and VPN neurons discharged individual action potentials that were temporally matched with each VN spike. Premotor VPP neurons did not show this firing pattern but rather showed activity that was predictive of the duration of fictive calls. Intracellular recordings of the soma-dendritic compartment of VPP and VPN neurons are needed to determine whether membrane oscillations and sustained depolarizations underlie VPN frequency and VPP duration coding, respectively, as shown for midshipman [Chagnaud et al., 2011].

Vocal premotor neurons connected to hindbrain auditory sites have been identified in several orders of teleost fishes [see Bass et al., 1994, and this report for toadfishes, Batrachoidiformes, Carlson and Bass, 2000, for squirrelfishes, Scorpaeniformes, and Ladich and Bass, 1996, for catfishes, Siluriformes]. While the general pattern of vocal premotor and motor organization is similar between Gulf toadfishes and plainfin midshipman fishes (the two species of toadfishes so far investigated), there are prominent differences which are highlighted, in part, in figure 7.

First, toadfish vocal motoneurons have extensive dendritic branching, especially lateral to the $\mathrm{VMN}$ where they overlap VPN somata, dendrites, and axons (fig. 2, 7c left). Vocal motoneurons in midshipman have modest den-
60

Brain Behav Evol 2014;84:51-65 DOI: $10.1159 / 000362916$
Chagnaud/Bass 

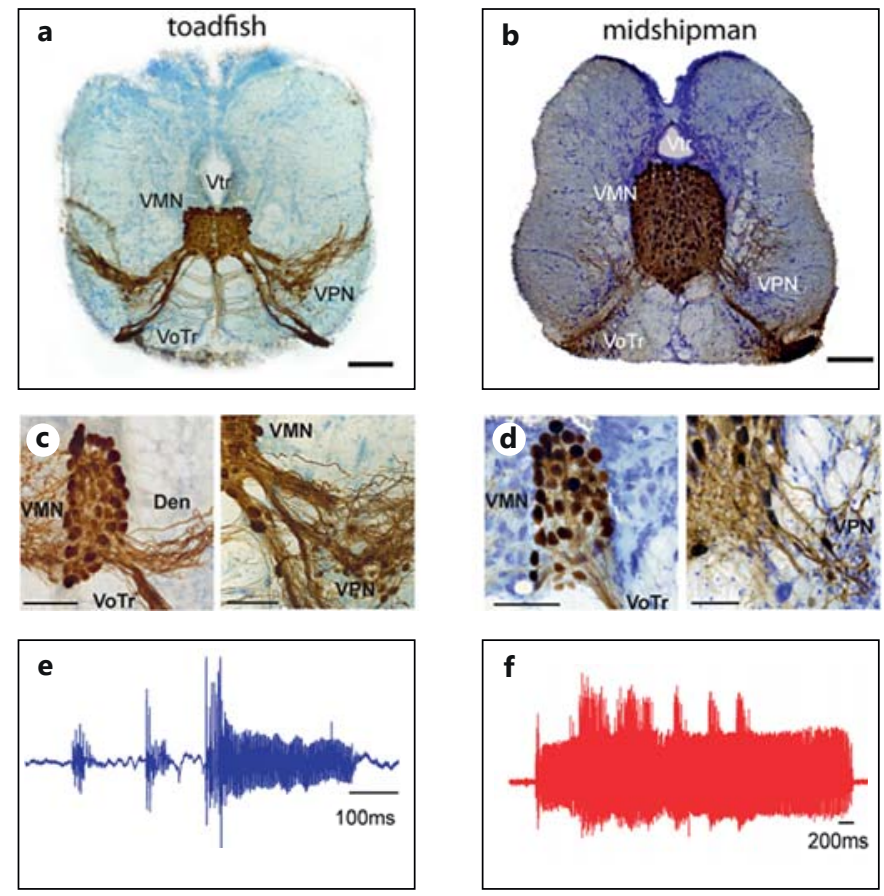

Fig. 7. Anatomical and vocal behavior comparisons between the Gulf toadfish and the plainfin midshipman fish. a, b Transverse sections of the transneuronally labeled vocal motor-pacemaker neuron (VMN-VPN) circuit in the toadfish (neurobiotin label from fig. 4a) and midshipman [biocytin label from fig. 1e of Chagnaud et al., 2011; also see Bass et al., 1994] at about the same hindbrain level. Scale bars $=200 \mu \mathrm{m}$. c, $\mathbf{d}$ Unilateral dextran-biotin labeling (left photographs) of VMN showing extensive dendritic branching (Den) outside of VMN in the Gulf toadfish (c, reverse image of fig. 3b) but not in the midshipman fish (d) [unpubl. data from Bass et al., 1994]. Transneuronal labeling (right photographs) shows a more prominent VPN column in toadfishes (expanded view from a) compared to midshipman (expanded view from $\mathbf{b}$ ). Scale bars $=100 \mu \mathrm{m}$ (left photographs in c, d), $100 \mu \mathrm{m}$ (right photograph in c) and $45 \mu \mathrm{m}$ (right photograph in d). e, f Gulf toadfish boatwhistle and plainfin midshipman growl vocalizations shown to highlight patterns of AM.

dritic arbors with little extension outside of VMN (fig. 7d left) [Bass and Baker, 1990; Bass et al., 1994].

Second, only midshipman exhibit dense transneuronal labeling of VPP somata and processes after labeling of the VN with either biocytin or neurobiotin [Bass et al., 1994, 1996]. In contrast to dextran-biotin, biocytin and neurobiotin cross gap junctions [see discussion in Bass et al., 1994]. The results imply more extensive gap junction coupling between VPP and the VPN-VMN circuit in midshipman.

Third, while the general pattern of vocal CPG connectivity to auditory and cerebellar structures is largely sim- ilar between midshipman and toadfishes [see Bass et al., 1994; Bass et al., 2000, for midshipman], Gulf toadfishes uniquely exhibit a prominent bundle of axons that is continuous with the VPN column at caudal levels and innervates the column of supramedullary neurons that are on the surface of the caudal hindbrain and rostral spinal cord. Single VPN and VPP fills did not reveal this connection; we expect that a more extensive intracellular labelling study will show a subset of VPN and/or VPP neurons projecting to the supramedullary column. The discovery of vocal CPG input to supramedullary neurons was unexpected, as this connection was not found in midshipman following extensive study of larval through adult stages [Bass et al., 1994, 1996; Knapp et al., 1999]. Supramedullary neurons are proposed to innervate mucous glands distributed across the body surface via several cranial nerves [Bennett et al., 1959; Funakoshi et al., 1995, 1998]. The functional significance of this vocal input remains to be shown, although increased mucous secretion might serve a protective function (e.g. avoidance of parasitic infection) linked to vocal signaling during intraspecific [Brantley and Bass, 1994] and interspecific [RemageHealey et al., 2006] agonistic encounters.

Fourth, the VPN column along the rostral-caudal extent of VMN is expansive along the medial-lateral axis in toadfishes; this column is largely a diffuse population along most of the extent of VMN in midshipman (fig. 7ad). Species differences in the expanse of VPN do not appear to depend on the vocal muscle mass, which is similar for fishes of comparable size [see Brantley et al., 1993, for midshipman, and Walsh et al., 1995, for Gulf toadfishes].

Fifth, midshipman fishes appear to have a larger VMN neuron population. The juvenile Gulf toadfishes in the current study had total motoneuron counts close to 1,000 , comparable to the number in juvenile oyster toadfishes of a similar body size [1- to 2-year-old size class in Fine et al., 1984; also see Radtke et al., 1995]. Juvenile midshipman fishes of comparable body size have close to 4,000 motoneurons, like sexually mature adult midshipman fishes [Bass and Andersen, 1991]. Assuming that Gulf toadfishes, like oyster toadfishes, add motoneurons as they age and approach 2,000-2,500 vocal motoneurons as in adult oyster toadfishes [Fine et al., 1984], the numbers are still close to $40 \%$ greater in midshipman. There are two caveats to the above comparisons. First, the VMN neuron number in Gulf toadfishes may be underestimated given that the VMN cell size $(\sim 18 \mu \mathrm{m})$ was less than $50 \%$ of the section thickness (50 $\mu \mathrm{m})$. Second, the motoneuron number in midshipman was based on counts of myelinated axons in the VN that 
innervates the vocal muscles attached to the swim bladder [Bass and Andersen, 1991]; VMN axons are unbranched as they exit the brain and along the length of the VN (fig. 2d) [see Bass and Baker, 1991]. Despite these concerns, the available data are highly suggestive of species differences in VMN neuron number. The ratio of VPN to VMN neurons in juvenile Gulf toadfishes was close to 1:3; it is closer to 1:20 in juvenile midshipman fishes [Bass, unpubl. obs.]. The larger VMN population and VPN:VMN ratio in midshipman may relate to their ability to generate advertisement hums that can last for more than $1 \mathrm{~h}$ [Ibara et al., 1983; Brantley and Bass, 1994; Bass et al., 1999], compared to toadfish advertisement boatwhistles with durations in the order of a few hundred milliseconds [Thorson and Fine, 2002; Amorim, 2006] (fig. 1a, b).

\section{Vocal Motor Coupling to Auditory Nuclei}

Transneuronal labeling in both toadfishes (this report) and midshipman [Bass et al., 1994] indicates that the vocal CPG network provides direct input to hindbrain auditory nuclei, including the OEN that directly innervates the inner ear and lateral line organs. In midshipman, single neuron fills show that duration-coding VPP neurons are the principal source of input to the efferent nucleus [Chagnaud et al., 2011]. This finding is consistent with neurophysiological evidence for the robust transfer of duration information by OEN neurons to the auditory (saccule) hair cell epithelium during vocalization, which is hypothesized to decrease auditory reafference [Weeg et al., 2005; Chagnaud and Bass, 2013].

Pacemaker neurons are the only premotor neurons robustly labeled via transneuronal transport in Gulf toadfishes, suggesting that the dense terminal-like varicosities observed in both VPP (see above) and auditory-related nuclei [e.g. DOri, see Bass et al., 2000, 2001] mainly originate from VPN, and not VPP as in midshipman. More extensive single cell anatomy studies of VPN and VPP coupled to intracellular records of target neurons (DOri and OEN) in toadfishes are needed to more rigorously test a predominant role for VPN in vocal coupling to the inner ear and lateral line. Recent intracellular recording studies in midshipman have shown that the VPP is the source of a vocal corollary discharge that informs the auditory system about call duration [Chagnaud and Bass, 2013]. The results presented here for the Gulf toadfish suggest that duration and/or PRR information, both of which are contained within the VPN output, is/are being transferred to the inner ear and lateral line organs. As proposed in midshipman fishes [Chagnaud and Bass,
2013], the high fundamental frequency/PRR $(>150 \mathrm{~Hz})$ code of the Gulf toadfish will ultimately be turned into a duration code by OEN neurons via summation of excitatory postsynaptic potentials, due to the integrative membrane properties of OEN neurons and the high frequency of VPN activity.

\section{Species-Specific Vocalizations and Vocal Network}

Circuitry

Both Gulf toadfish and plainfin midshipman produce brief agonistic grunts that resemble each other in their physical characters (see Introduction for references). By contrast, several features distinguish toadfish and midshipman advertisement calls, including call duration and FM and AM patterns. Toadfishes produce advertisement boatwhistles with durations of a few hundred milliseconds, and a prominent pattern of FM and AM (fig. 1a, 7e). The sequences of grunts-hoots in the boatwhistles of oyster toadfishes [see Edds-Walton et al., 2002] and of grunts-hoots-grunts in the boatwhistles of the Gulf toadfish and the Lusitanian toadfish (Halobatrachus didactylus) [e.g. Thorson and Fine, 2002; Amorim, 2006] are largely invariant for each of these species [Amorim, 2006; Rice and Bass, 2009]. Midshipman advertisement hums display minimal FM and AM and can be several orders of magnitude longer in duration, lasting for minutes to $>1 \mathrm{~h}$ (fig. 1b) [Ibara et al., 1983; Brantley and Bass, 1994; McIver et al., 2014]. Midshipman hums essentially have only a hoot-like segment (fig. 1b). The only midshipman call with an FM/AM pattern comparable to that of a boatwhistle is the agonistic growl that is a combination of grunt and hum/hoot-like segments (fig. 7f). However, unlike boatwhistles, the duration and temporal order of the grunt-hoot sequence of growls varies widely within and between individuals [McIver et al., 2014]. In sum, the available evidence indicates that the spatiotemporal patterning of calls with prominent FM and AM segments is more invariant in toadfishes than in midshipman. We recognize that the duration or degree of AM may vary between individuals in a species [e.g. Amorim, 2006], but the sequence of either a broadband grunt followed by a multiharmonic hoot, as in the Gulf toadfish, or a hoot bracketed by grunts, as in the Lusitanian toadfish, is largely invariant and very different from the growl of midshipman (fig. 7e, f).

Ultimately, the long-term goal here is to understand how species diversity in vocal CPG traits leads to divergence in the spectro-temporal pattering of acoustic signals among toadfishes and fishes in general, and how this relates to the central patterning of the more complex 
vocalizations of tetrapods. Comparisons between the current study of Gulf toadfishes and prior ones of plainfin midshipman fishes lead us to propose that: (1) the more expansive dendritic arbor of motoneurons that extensively overlaps an expansive frequency-coding VPN column in the Gulf toadfish contributes to stronger coupling throughout the VMN-VPN circuit which, in turn, is essential for generating stable calls exhibiting prominent FM and AM segments in the Gulf toadfish, (2) robust gap-junction coupling between duration-coding VPP neurons and the VPN-VMN circuit in plainfin midshipman fishes contributes to their ability to generate advertisement calls lasting for minutes to at least $1 \mathrm{~h}$, and (3) vocal coupling to the inner ear and lateral line systems originates mainly from frequency-coding VPN neurons in the Gulf toadfish and duration-coding VPP neurons in the plainfin midshipman. In both species, however, the integrative properties of OEN neurons assure a vocal corollary discharge encoding call duration [Chagnaud and Bass, 2013], one of the most salient cues in auditory perception in vertebrates, including fishes. Importantly, we emphasize that these and related hypotheses are testable using more quantitative neurophysiological methods as we have done in studies of midshipman fishes [Chagnaud et al., 2011, 2012; Chagnaud and Bass, 2013].

\section{Concluding Comments}

While comparative studies have investigated the role of peripheral neuromuscular mechanisms in generating the diversity of vocalizations within individual vertebrate lineages [Suthers et al., 1999; Elemans et al., 2008; Leininger and Kelley, 2013], there are few comparable studies of central mechanisms [e.g. Bass and Baker, 1991; Striedter, 1994; Jarvis et al., 2000; Goodson and Bass, 2002; Arriaga et al., 2012]. Fishes present an excellent vertebrate model to investigate how hindbrain mechanisms contribute to species level differences in vocal characters due to the evolutionarily conserved organization of vocal compartments in the vertebrate hindbrain [Bass et al., 2008; Bass and Chagnaud, 2012] and the simplicity of fish sounds (fig. 1a, b) and sound-producing mechanisms (see above). The present report and prior studies of midshipman fishes (see Introduction) provide, to our knowledge, the first comparative morphophysiological analysis of the hindbrain CPG for vocalization between species within a single order of vertebrates. A prior study emphasized similarities between Gulf toadfishes and the plainfin midshipman in descending forebrain and midbrain vocal-acoustic connectivity [Goodson and Bass, 2002]. Cellular neurophysiological studies of vocal forebrain and midbrain sites like those completed for the vocal CPG of these species may yet reveal diverse neurophysiological characters that contribute to the patterning of vocal CPG output [Goodson and Bass, 2000a-c; Kittelberger et al., 2006].

More comparative data on different toadfish species together with data on fishes from different orders [Ladich and Fine, 2006; Bass and Ladich, 2008], with similar and different sound-producing mechanisms, are needed in order to substantiate the current hypothesis that the frequency and duration of vocalizations in fishes are encoded in separate neuronal populations as shown in toadfishes [Chagnaud et al., 2011; this report]. Transneuronal nerve labeling reveals that the somatodendritic-axonal organization of the VPP-VPN-VMN network documented here for the Gulf toadfish is observed in at least two other species of toadfishes, i.e. the oyster toadfish [Bass et al., 2008] and the three-spined toadfish Batrachomoeus trispinosus [Bass, unpubl. obs.]. However, the vocalizations of these and other toadfish species diverge in the specific details of FM and AM patterns [see Amorim, 2006; Rice and Bass, 2009; Mosharo and Lobel, 2012]. What accounts for such divergence? We suggest that the fine-tuning of intrinsic and network properties in one or more of the vocal CPG nuclei, dependent in part on anatomical properties (e.g. the extent of gap junction coupling within and between vocal CPG nuclei or the abundance of excitatory synapses from VPN to VMN), determine microstructural differences in vocal attributes among toadfishes and, more generally, among other vocal fishes and lineages of vocal vertebrates.

\section{Acknowledgements}

The authors thank M. Marchaterre for all of the histology following nerve labels, P. Edds-Walton for providing the juvenile toadfishes used for nerve labels, L. Remage-Healey for the Gulf toadfish and M. Marchaterre for the plainfin midshipman sound recordings, M. Fine and P. Walsh for correspondence on sonic muscle mass, R. Banchi, N. Feng, and J. Tripp for comments on a previous version of this paper, and C. Gravot for the schematic in figure 1c. We further thank the two anonymous reviewers whose comments/suggestions helped improve this paper. Research support was obtained from NSF (BNS 9021563 and IOS 1120925) and from the Deutsche Forschungsgemeinschaft (DFG; SFB 870 TPB17). 


\section{References}

Amorim MCP (2006): Diversity in sound production in fish; in Ladich F, Collin SP, Moller P, Kapoor BG (eds): Communication in Fishes. Enfield, Science, vol 1, pp 71-106.

-Arriaga G, Zhou EP, Jarvis ED (2012): Of mice, birds, and men: the mouse ultrasonic song system has some features similar to humans and song-learning birds. PLoS One 7:e46610.

- Bass AH (1989): Evolution of vertebrate motor systems for acoustic and electric communication: peripheral and central elements. Brain Behav Evol 33:237-247.

Bass AH, Andersen K (1991): Intra- and intersexual dimorphisms in the sound generating motor system in a vocalizing fish: motor axon number and size. Brain Behav Evol 37:204214.

- Bass AH, Baker R (1990): Sexual dimorphisms in the vocal control system of a teleost fish: morphology of physiologically identified neurons. J Neurobiol 21:1155-1168.

Bass AH, Baker R (1991): Evolution of homologous traits. Brain Behav Evol 38:240-254.

Bass AH, Baker R (1997): Phenotypic specification of hindbrain rhombomeres and the origins of rhythmic circuits in vertebrates. Brain Behav Evol 50:3-16.

Bass AH, Bodnar DA, Marchaterre MA (1999): Complementary explanations for existing phenotypes in an acoustic communication system; in Hauser M, Konishi M (eds): Neural Mechanisms of Communication. Cambridge, MIT Press, pp 493-514.

Bass AH, Bodnar DA, Marchaterre MA (2000): Midbrain acoustic circuitry in a vocalizing fish. J Comp Neurol 419:505-531.

- Bass AH, Bodnar DA, Marchaterre MA (2001): Acoustic nuclei in the medulla and midbrain of the vocalizing Gulf toadfish (Opsanus beta). Brain Behav Evol 57:63-79.

Bass AH, Chagnaud BP (2012): Shared developmental and evolutionary origins for neural basis of vocal-acoustic and pectoral-gestural signaling. Proc Natl Acad Sci USA 109: 10677-10684.

Bass AH, Chagnaud BP, Feng N (in press): Comparative neurobiology of sound production in fishes; in Ladich F (ed): Sound Communication in Fishes. Berlin, Springer.

Bass AH, Gilland EH, Baker R (2008): Evolutionary origins for social vocalization in a vertebrate hindbrain-spinal compartment. Science 321:417-421.

Bass AH, Horvath BJ, Brothers EB (1996): Nonsequential developmental trajectories lead to dimorphic vocal circuitry for males with alternative reproductive tactics. J Neurobiol 30 : 493-504.

Bass AH, Ladich F (2008): Vocal-acoustic communication: from neurons to behavior; in Webb JF, Fay RR, Popper AN (eds): Fish Bioacoustics. Berlin, Springer, pp 253-278.

- Bass AH, Marchaterre MA, Baker R (1994): Vocal-acoustic pathways in a teleost fish. J Neurosci 14:4025-4039.
Bennett MVL, Crain SM, Grundfest H (1959): Electrophysiology of supramedullary neurons in Spheroides maculatus. 1. Orthodromic and antidromic responses. J Gen Physiol 43: 159-188.

Bennett MVL, Pappas GD (1965): Neurophysiology and ultrastructure of a synchronously firing nucleus in toadfish, Opsanus. Fed Proc 24: 462.

Bennett NT, Weiser M, Baker R, Bennett MVL (1985): Toadfish sonic motor system. 1. Physiology. Bio Bull 169:546.

Boyle KS, Dewan AK, Tricas TC (2013): Fast drum strokes: novel and convergent features of sonic muscle ultrastructure, innervation, and motor neuron organization in the pyramid butterflyfish (Hemitaurichthys polylepis). J Morphol 274:377-394.

Bradbury J, Vehrencamp S (2011): Principles of animal communication. Sunderland, Sinauer.

Brantley RK, Bass AH (1994): Alternative male spawning tactics and acoustic signals in the plainfin midshipman fish, Porichthys notatus (Teleostei, Batrachoididae). Ethology 96:213232.

Brantley RK, Tseng J, Bass AH (1993): The ontogeny of inter- and intrasexual vocal muscle dimorphisms in a sound-producing fish. Brain Behav Evol 42:336-349.

Carlson BA, Bass AH (2000): Sonic/vocal motor pathways in squirrelfish (Teleostei, Holocentridae). Brain Behav Evol 56:14-28.

Chagnaud BP, Bass AH (2013): Vocal corollary discharge communicates call duration to vertebrate auditory system. J Neurosci 33:1877511878.

Chagnaud BP, Baker R, Bass AH (2011): Vocalization frequency and duration are coded in separate hindbrain nuclei. Nat Commun 2: 346.

Chagnaud BP, Zee MC, Baker R, Bass AH (2012): Innovations in motoneuron synchrony drive rapid temporal modulations in vertebrate acoustic signaling. J Neurophysiol 107:35283542 .

Cohen MJ, Winn HE (1967): Electrophysiological observations on hearing and sound production in the fish, Porichthys notatus. J Exp Zool 165:355-369.

Demski LS, Gerald JW (1972): Sound production evoked by electrical stimulation of the brain in toadfish (Opsanus beta). Anim Behav 20: 507-513.

Demski LS, Gerald JW (1974): Sound production and other behavioral effects of midbrain stimulation in free-swimming toadfish, Opsanus beta. Brain Behav Evol 9:41-59.

Demski LS, Gerald JW, Popper AN (1973): Central and peripheral mechanisms of teleost sound production. Am Zool 13:1141-1167.

Edds-Walton PL, Mangiamele LA, Rome LC (2002): Variations of pulse repetition rate in boatwhistle sounds from oyster toadfish, $O p$ sanus tau, around Waquoit bay, Massachusetts. Bioacoustics 13:153-173.
Elemans CPH, Mead AF, Rome LC, Goller F (2008): Superfast vocal muscles control song production in songbirds. PLoS One 3:e2581.

- Fine M, Economos D, Radtke R, McClung J (1984): Ontogeny and sexual dimorphism of motor nucleus in the oyster toadfish. J Comp Neurol 255:105-110.

Fine ML, Thorson RF (2008): Use of passive acoustics for assessing behavioral interactions in individual toadfish. Trans Am Fish Soc 137:627-637.

Fish MP, Mowbray WH (1970): Sounds of Western North Atlantic fishes. Baltimore, Johns Hopkins Press.

Funakoshi K, Abe T, Kishida R (1995): Trigeminal, vagal, and spinal projections of supramedullary cells in the puffer fish, Takifugu niphobles. J Comp Neurol 358:552-562.

Funakoshi K, Kadota T, Atobe Y, Nakano M, Goris RC, Kishida R (1998): Gastrin/CCK-ergic innervation of cutaneous mucous gland by the supramedullary cells of the puffer fish Takifugu niphobles. Neurosci Lett 258:171174

Goodson JL, Bass AH (2000a): Vasotocin innervation and modulation of vocal-acoustic circuitry in the teleost Porichthys notatus. J Comp Neurol 422:363-379.

Goodson JL, Bass AH (2000b): Rhythmic midbrain-evoked vocalization is inhibited by vasoactive intestinal polypeptide in the teleost Porichthys notatus. Brain Res 865:107-111.

Goodson JL, Bass AH (2000c): Forebrain peptides modulate sexually polymorphic vocal circuitry. Nature 403:769-772.

Goodson JL, Bass AH (2002): Vocal-acoustic circuitry and descending vocal pathways in teleost fish: convergence with terrestrial vertebrates reveals conserved traits. J Comp Neurol 448:298-322.

Greenfield DW, Winterbottom R, Collette BB (2008): Review of the toadfish genera (Teleostei: Batrachoididae). Proc Calif Acad Sci 59: 665-710.

Highstein SM (1992): The efferent control of the organs of balance and equilibrium in the toadfish, Opsanus tau. Ann NY Acad Sci 656: 108-123.

-Highstein SM, Baker R (1986): Organization of the efferent, vestibular nuclei and nerves of the toadfish, Opsanus tau. J Comp Neurol 243:309-325.

- Ibara RM, Penny LT, Ebeling AW, van Dykhuizen G, Cailliet G (1983): The mating call of the plainfin midshipman fish, Porichthys notatus; in Noakes DLG, Lindquist DG, Helfman GS, Ward JA (eds): Predators and Prey in Fishes. The Hague, Junk, pp 205-212.

-Jarvis ED, Ribeiro S, da Silva ML, Ventura D, Vielliard J, Mello CV (2000): Behaviourally driven gene expression reveals song nuclei in hummingbird brain. Nature 406:628-632.

Kittelberger JM, Land BR, Bass AH (2006): Midbrain periaqueductal gray and vocal patterning in a teleost fish. J Neurophysiol 96:71-85. 
Knapp R, Marchaterre MA, Bass AH (1999): Early development of the motor and premotor circuitry of a sexually dimorphic vocal pathway in a teleost fish. J Neurobiol 38:475-490.

Ladich F, Bass AH (1996): Sonic/vocal-acousticolateralis pathways in teleost fishes: a transneuronal biocytin study in mochokid catfish. J Comp Neurol 374:493-505.

Ladich F, Fine ML (2006): Sound-generating mechanisms in fishes: a unique diversity in vertebrates; in Ladich F, Collin SP, Moller P, Kapoor BG (eds): Communication in Fishes. Enfield, Science, vol 1, pp 3-43.

Leininger EC, Kelley DB (2013): Distinct neural and neuromuscular strategies underlie independent evolution of simplified advertisement calls. Proc Biol Sci 280;20122639.

Maruska K, Mensinger A (2009): Acoustic characteristics and variations in grunt vocalizations in the oyster toadfish Opsanus tau. Environ Biol Fish 84:325-337.

-McIver E, Marchaterre M, Rice A, Bass A (2014): Novel underwater soundscape: acoustic repertoire of plainfin midshipman fish. J Exp Biol 2014;217:2377-2389.

Mosharo K, Lobel P (2012): Acoustic signals of two toadfishes from Belize: Sanopus astrifer and Batrachoides gilberti (Batrachoididae). Environ Biol Fish 94:623-638.

Nowicki S, Westneat M, Hoese W (1992): Birdsong: motor function and the evolution of communication. Semin Neurosci 4:385-390.
Onuki A, Somiya H (2007): Innervation of sonic muscles in teleosts: occipital versus spinal nerves. Brain Behav Evol 69:132-141.

Pappas G, Bennett M (1966): Specialized junctions involved in electrical transmission between neurons. Ann NY Acad Sci 137:495508.

Radtke R, Fine M, Bell J (1995): Somatic and otolith growth in the oyster toadfish (Opsanus tau L.). J Exp Mar Biol Ecol 90:259-275.

Remage-Healey L, Bass AH (2005): Rapid elevations in both steroid hormones and vocal signaling during playback challenge: a field experiment in Gulf toadfish. Horm Behav 47: 297-305.

Remage-Healey LH, Bass AH (2006): From social behavior to neurons: rapid modulation of advertisement calling and vocal pattern generators by steroid hormones. Horm Behav 50: 432-441.

Remage-Healey L, Nowacek DP, Bass AH (2006): Dolphin foraging sounds suppress calling and elevate stress hormone levels in a prey species, the Gulf toadfish. J Exp Biol 209:4444-4451.

Rice AN, Bass AH (2009): Novel vocal repertoire and paired swim bladders of the three-spined toadfish, Batrachomoeus trispinosus: insights into the diversity of the Batrachoididae. J Exp Biol 212:1377-1391.

Skoglund CR (1961): Functional analysis of swim-bladder muscles engaged in sound production of the toadfish. J Biophys Biochem Cytol 10:187-200.
Striedter GF (1994): The vocal control pathways in budgerigars differ from those in songbirds. J Comp Neurol 343:35-56.

Suthers R, Goller F, Pytte C (1999): The neuromuscular control of birdsong. Philos Trans $\mathrm{R}$ Soc Lond B Biol Sci 354:927-939.

Tavolga WN (1958): Underwater sounds produced by two species of toadfish, Opsanus tau and Opsanus beta. Bull Mar Sci 8:278-284.

Thorson RF, Fine ML (2002): Crepuscular changes in emission rate and parameters of the boatwhistle advertisement call of the Gulf toadfish, Opsanus beta. Environ Biol Fish 63: 321-331.

Walsh PW, Mommsen TP, Bass AH (1995): Biochemical and molecular aspects of singing in batrachoidid fishes; in Hochachka PW, Mommsen TP (eds): Biochemistry and Molecular Biology of Fishes. Amsterdam, Pergamon Press, vol 4, pp 279-289.

Weeg MS, Land BR, Bass AH (2005): Vocal pathways modulate efferent neurons to the inner ear and lateral line. J Neurosci 25:5967-5974.

Weiser M, Bennett NT, Bennett MVL, Baker R (1985): Toadfish sonic motor system. 2. Morphology. Biol Bull 169:556-557.

- Yager DD (1992): Underwater acoustic communication in the African pipid frog Xenopus borealis. Bioacoustics 4:1-24.

Zornik E, Kelley DB (2008): Regulation of respiratory and vocal motor pools in the isolated brain of Xenopus laevis. J Neurosci 28:612621 